\title{
Research on Measurement and Control System of Common Parameters of Agricultural Equipment Based on Wireless Transmission
}

\author{
Fan Wu, School of Electrical Engineering, Yancheng Institute of Technology, Yancheng, China \\ Aiqin Li, School of Electrical Engineering, Yancheng Institute of Technology, Yancheng, China \\ Saihua He, Jiangsu Linyang Energy Co., Ltd., Nantong, China \\ Mohammad Ikbal, Lovely Professional University, Jalandhar, India \\ (iD) https://orcid.org/0000-0001-6148-1555
}

Mohamed A. Sharaf Eldean, Energy Engineering Department, Suez University, Egypt

\begin{abstract}
To resolve the limited transmission and complicated layout, the common parameter measurement and control system of agricultural equipment use virtual instrument technology and embedded technology. The research results show that the wireless transmission data of the system is accurate and reliable. The linearity errors of acquisition divestiture (AD) and frequency counting (FI) channel measurements are only $0.38 \%$ and $0.006 \%$, respectively, and the resolution is $0.01 \mathrm{~V}$ and $1 \mathrm{~Hz}$. This performance evaluation fully meets equipment detection in agricultural use. The system is integrated with various wireless transmission platforms, intelligent agricultural equipment, and computer wireless reception and processing. These parameters can significantly improve the automation level and quality of agricultural equipment.
\end{abstract}

\section{KEYWORDS}

Data Collection, Equipment Information, Retrieval Device, Wireless Transmission

\section{INTRODUCTION}

The best embodiment of the joint development of measurement and control technology and computer technology is the virtual instrument technology. An important symbol of the development of instruments has begun to be applied to the automatic control and performance testing of agricultural equipment(Wan et al., 2020). There are also certain differences in the development of detection systems as different detection tasks that use different agricultural equipment are different. The number of pulses, frequency signals, voltage virtual signals, and character display signals represents the input system received from each sensor from the different signals (Rao et al., 2020). The analysis 
is done to choose different signals that meet the performance of their respective systems to receive different sensor signals from different agricultural equipment. To avoid the need to research and develop multiple detection systems to detect multiple agricultural equipment's, and make full use of the system is discussed in Jiang et al., 2020. Traditional agricultural equipment testing instruments have shortcomings such as limited transmission, difficulty in real-time monitoring, and cumbersome wiring. Agricultural machinery for field operations of agricultural equipment, moving and detecting while moving, will generate high-frequency vibration and huge noise. In this case, the detection effect is not good, and it cannot be compared with indoor work and professional detection. Most of the ordinary detection equipment cannot finish the work. It is necessary to develop equipment specially used for performance testing of agricultural equipment to improve the reliability of testing equipment. Therefore, the best way to solve these practical engineering problems is to develop a portable wireless transmission measurement and control system.

This design solves the problems of single instrument function, poor work reliability, and inability to process data.

- Virtual instrument technology

- Embedded technology

should be used to design multiple wireless transmission methods. To achieve intelligent transmission equipment, common data collection, computer wireless reception, and processing, agricultural equipment is designed in this paper. The article is thus organized in the following order. A literature review of various techniques and procedures is detailed in Section 2. Section 3 discusses the different methods and hardware designs to analyze the system. Section 4 discusses the experimental results of the present structure. Finally, the manuscript is concluded in Section 4.

\section{LITERATURE REVIEW}

A compensation topology parameter of optimization design based on an anti-bias performance optimization scheme is proposed in Sani M. I. et al., 2016. In this scheme, two freely adjustable variables $\mathrm{K} 1$ and $\mathrm{K} 2$ are used to optimize the compensation network parameters of the wireless power transmission system. The system can automatically adjust the transmitting current of the primary coil and keep the output power relatively stable. A $120 \mathrm{~W}$ experimental prototypes were built when the lateral offset percentage of the coil is less than $35 \%$. The maximum fluctuation rate of the system output power is kept within 10\%, and the efficiency of the whole machine is kept above $81 \%$ (Wang et al., 2019). Gao, Q. et al. designed an automatic roll position adjustment system that can predict roll parameters. The system adopts automatic control technology, sensor technology, and industrial communication technology, and takes a high-performance PLC controller as the control core. PLC (S7-1500) controls the three-phase asynchronous motor to drive the gear connected with reducer and coupling. The drive roll connects with the upper and lower horizontal shafts to move. PCA-BP algorithm is used to train the roll parameter prediction model to predict the roll parameters of the given square pipe model(Wang et al., 2019). The system can predict the corresponding roll parameters according to the specifications of the new type of square tube and adjust automatically. The system not only improves the adjustment speed and precision but also avoids the waste of manpower, thus greatly improving the production efficiency of enterprises(De Wagter et al., 2018). Yan, H. et al proposed a nonlinear adaptive inverse step control method. PMSM1 with 5th and 7th harmonics and PMSM2 without 5th and 7th harmonics are derived to reduce the torque pulse generated by 5 th and 7 th harmonics. The simulation comparison with the PI controller shows that the adaptive inverse step control scheme can provide conditions for decoupling control of two serial motors, inhibit parameter change and load disturbance, and have better responsiveness, robustness, and tracking performance.

Displaying data in a coherent format is key for final users to understand what is happening in the field. The most common way to display agricultural data has been in the format of maps, as 
mapping is useful to define spatial trends and homogeneous zones. However, displaying agronomical information in beautiful maps should not be the goal of map generation. Maps need to be useful for making decisions, they need to be a help to answer a question, providing an interpretation of spatial information (Basnet B. and Bang J.2018). The goal of building maps is obtaining a few management zones with the parameters of interest so that a treatment can be efficiently applied. To get plausible management zones, kriging is one of the most used interpolation techniques to delimit areas of manageable sizes (Adamchuk, V.I. et al., .2004.)Taking into account the considerable amount of data that Smart Farming generates, there are many software applications to cope with interpolation, in general, or kriging in particular (Oliver, M.; Webster, R..2014). Also, when building a map, a coordinate system needs to be supplied along with the map. One ideal alternative for agricultural maps is brought by the Local Tangent Plane (LTP) coordinate system, which features Euclidean geometry, allows user-set origins, and employs the intuitive coordinate frame east-north. Regarding the coding and display of data in the maps, grids allow the systematic quantization of the LTP coordinate system to manage crop production information more efficiently, facilitating the exchange of information among successive seasons and the comparison of multiple parameters on the same field (Spencer, D.B., 2005.). A practical example of grid-based maps using LTP coordinates is shown in Figure 3. Taking into account the key role of positioning systems, a map-based approach is the method in which a Global Positioning System (GPS)or any other Global Navigation Satellite System (GNSS) - receiver and a data logger (e.g., an onboard computer) are used to record the position of a particular measurement (georeferenced data), so several maps can be generated and processed along with other layers of spatially variable information (Adamchuk, V.I.;et.al .2014). In general, GNSS receivers are the universal position devices used to build maps; however, in some cases, for example in greenhouses or dense fields of tall trees, GNSS is not the best option to use due to the difficulty of getting signals with reliable accuracy; so, in some cases, alternative solutions such as machine vision must be implemented (Cossell, S.; 2016)

\section{RESEARCH METHODOLOGY}

\subsection{General Design Parameters of The System}

The wireless data transmission technologies selected in this article mainly include Wireless Fidelity (Wi-Fi), General Packet Radio Service (GPRS), Global System for Mobile Communications (GSM), ZigBee, and Bluetooth, etc. According to the comparative analysis of their respective usage, these several technologies have their advantages and disadvantages. The specific technical comparison analysis is shown in the following table.It can be seen from the above table that GPRS is mainly used for large data volume and long-distance transmission. Its application occasions the upper and lower computers are far away, transmission cannot be realized by ZigBee mode. The parameter detection in the cell phone signal coverage area can use GPRS. If the detection range is relatively large, such as testing throughout China or calculating the workload of searching a larger area, then GPRS can be used at this time (Tripathi and De, 2018). However, GPRS also has conditions for use. Its host computer must have a fixed port to connect to the Internet and be positioned at that point. The location cannot be changed at will; this method will charge a corresponding fee based on the consumed traffic, so the use cost is higher than the ZigBee method.

The characteristic of GSM receiving and sending is that it can be applied in a relatively long distance. Although GSM has the same transmission distance as GPRS, the transmission speed is only 1110 of GPRS(Zheng et al., 2019). The advantage is that there is no need for a fixed port number and Internet Protocol (IP) address. The working place of the host computer can be moved at any time, and there is no need to connect to the Internet, and data can be sent directly to the mobile phone. GSM does not need to be tested anytime and anywhere. Unlike ZigBee and GPRS, which are subject to different venues, such as agricultural products service venues, the amount of information retrieved is 
Table 1. Comparison of the characteristics of wireless transmission modes

\begin{tabular}{|l|l|l|l|l|}
\hline \multirow{2}{*}{ Parameter } & \multicolumn{4}{c|}{ Wireless Transmission Method } \\
\cline { 2 - 5 } & \multicolumn{1}{|c|}{ GPRS/GSM } & \multicolumn{1}{c|}{ Wi-Fi } & \multicolumn{1}{c|}{ Bluetooth } & \multicolumn{1}{c|}{ ZigBee } \\
\hline Application field & $\begin{array}{l}\text { WAN, voice, and } \\
\text { data }\end{array}$ & $\begin{array}{l}\text { Web, mail, and } \\
\text { video }\end{array}$ & $\begin{array}{l}\text { Replace peripheral } \\
\text { cables }\end{array}$ & $\begin{array}{l}\text { Monitoring and } \\
\text { control }\end{array}$ \\
\hline System resource & $>16 \mathrm{MB}$ & $>1 \mathrm{MB}$ & $>250 \mathrm{~Kb}$ & $4 \sim 60 \mathrm{~Kb}$ \\
\hline Battery life & $1 \sim 7$ & $1 \sim 7$ & $100 \sim 1000$ \\
\hline Network node & 1 & $0.5 \sim 5$ & 8 & 65535 \\
\hline $\begin{array}{l}\text { Data transfer rate } \\
\text { (kb/s) }\end{array}$ & $64 \sim 128$ & 32 & 720 & $20 \sim 250$ \\
\hline $\begin{array}{l}\text { Transmission range } \\
\text { (m) }\end{array}$ & 1000 & 11000 & $1 \sim 10$ & $1 \sim 100$ \\
\hline Advantage & $\begin{array}{l}\text { Large coverage and } \\
\text { high data quality }\end{array}$ & Fast and flexible & $\begin{array}{l}\text { Low cost and easy } \\
\text { to use }\end{array}$ & $\begin{array}{l}\text { High reliability, low } \\
\text { power consumption, } \\
\text { low cost }\end{array}$ \\
\hline $\begin{array}{l}\text { Disadvantage } \\
\text { Large delay and high } \\
\text { power consumption }\end{array}$ & $\begin{array}{l}\text { High power } \\
\text { consumption and } \\
\text { short distance }\end{array}$ & $\begin{array}{l}\text { Close distance, high } \\
\text { power consumption }\end{array}$ & Closer \\
\hline
\end{tabular}

small, and what is the situation at work. But it will cost according to the number of SMS messages sent and received as compared to various methods(Wang et al., 2019).

The ZigBee method is mainly used for short-distance measurement and control. It can meet the range of $100 \mathrm{~m}$. The distance between the machine, the equipment, and the amount of information retrieved is large, has a short distance, and requires real-time. It is used when reporting location and time information. It can detect equipment on-site and receive and send a larger range. For example, this method can be used to realize the wireless transmission of data to detect the upper computer located at the head of the field to receive the parameters of agricultural equipment working in the field (Zhang and Chen, 2018).

The transmission method should first consider using ZigBee during the actual use of the measurement and control system. If the task cannot be completed at this time, then GPRS can be considered. If the problem is still not resolved, only GSM short message service (SMS) can be used. Due to the complex retrieval of information by the equipment and the relatively large area of work, sending data cannot be completed by one method alone (Smith et al., 2019). Therefore, to complete the task, the above three methods can only be used together, and the three methods are combined to improve the stability of the wireless transmission. Solve the problem that can't be done using a certain method alone (Merk et al., 2015). Figure 1 shows the design of the wireless transmission system design and the common parameter measurement and control instrument for portable agricultural equipment. The commonality and usability of agricultural equipment measurement and control invented a portable measurement and control instrument, which has multiple measurement and control channels.

The special machine that can detect various related data, such as equipment speed, acceleration and displacement, engine speed, oil temperature, vibration frequency, environmental temperature and humidity, noise, wind force when the equipment is used, the size, location, current condition of the equipment, the tensile and compressive stress and bending torque of the equipment, the linear displacement, angular displacement, flow, fuel consumption, and other counting signals; and can be used Control virtual digital switch quantity.

The upper computer data analysis and processing system and two types of data transceiver modules can form a wireless transmission system. Different sending modes will cause different processing 
Figure 1. Block diagram of the measurement and control system

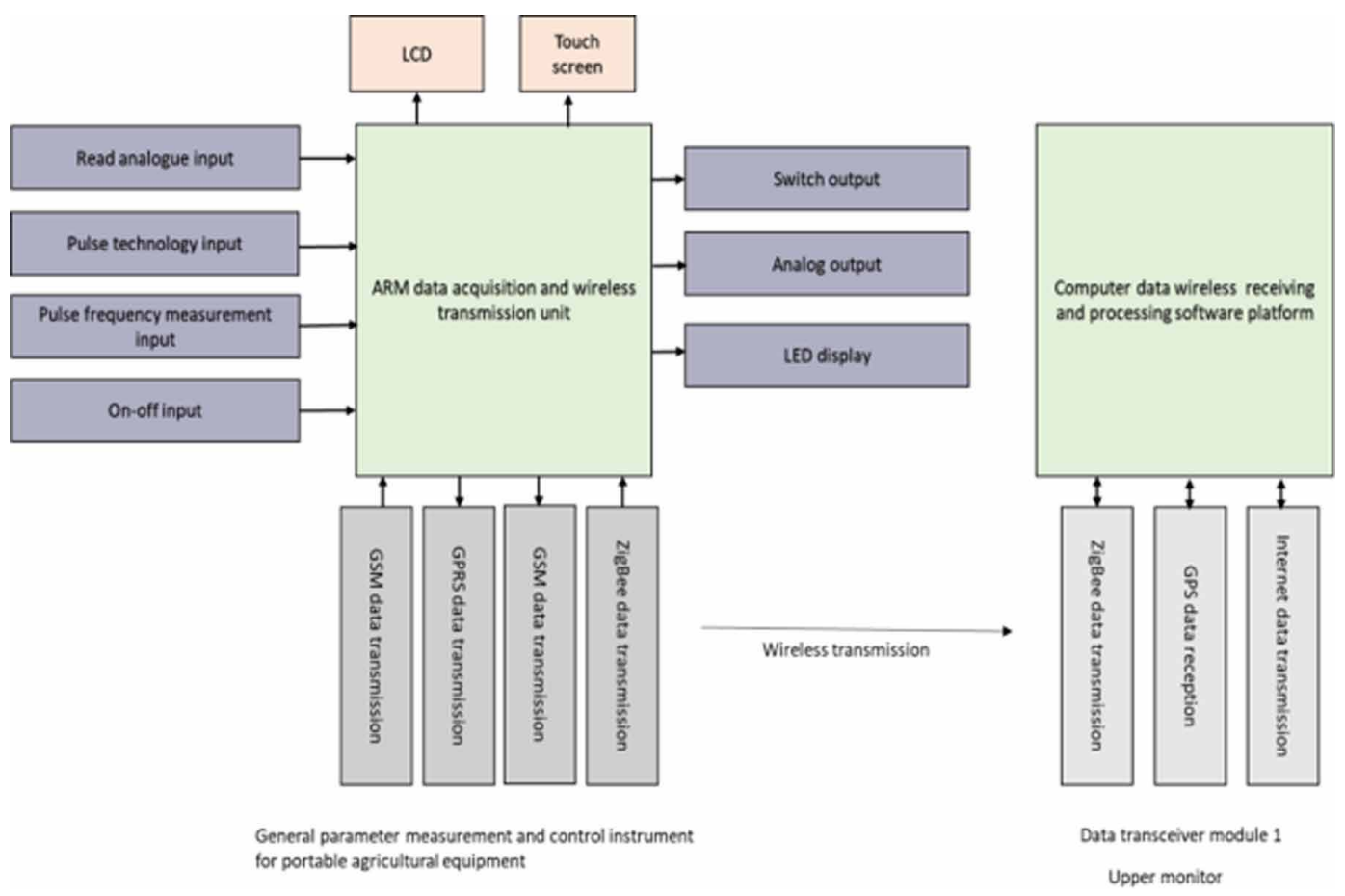

methods of module 1 , and then corresponding to the relative module, send and receive data to module 2 ; module 2 is responsible for sending and receiving the data sent by module 1 , and then pass it to the host computer (Ravi M. et al., 2007). The development of virtual instrument technology gave birth to a platform for computer data receiving and processing upper computer data analysis and processing software, which can display the analysis and storage results in a time when receiving data.

\subsection{System Hardware Design}

Using Samsung's processor is the core of this system, which can manage memory units. It is mainly used in handheld devices, high-cost performance, low consumption, and small functions. S3C 2410A has the following functions in the portable measurement and control instrument (Spencer, 2005):

- Eight-channel 10-bit ADC: Six channels are used for analog channels and two channels are used for the touch screen input interface.

- Twenty-four channels of external interrupt sources, five 16-bit timers: the counter of external pulse signals consists of four interrupt sources and a timer.

- One hundred and seventeen universal input/output ports: 16 ports can be selected arbitrarily, which can realize input and output of eight-way switch status.

- One internal LCD controller: different LCDs can display information on different channels.

To develop more functions, the following hardware devices are combined:

- Two programmable counter timers 8253 can receive six pulse signals at the same time.

- GPS can locate and display time.

- One-half GPRSSGSM module can directly send and receive data wirelessly. 
- Two ZigBee modules can realize data processing in a short distance.

\subsection{System Software Design}

The software design of the portable measurement and control instrument and the host computer is the main part of the software design. The software design of the measurement and control instrument can be divided into six subroutines, namely human-computer interaction interface, pulse counting, measuring frequency, GPS positioning, digital IIO, AD acquisition (Mallampati et al., 2018). The human-computer interaction interface is composed of three interfaces, which are the main interface, the interface for setting system parameters, and the interface for testing system data (Teimouri, N. et al.,.2018) When setting the system parameters, you first need to determine the number of collection points, channels and frequencies, then calculate the number of pulses and determine the pulse frequency, and finally choose a reasonable switch channel and wireless transmission mode. Figure 2 shows the entire process of software design for the measurement and control instrument.

The virtual instrument technology will be used when the computer wirelessly transmits data and when the computer processes the software platform, the two corresponding programs compiled by it both use Lab Windows CVI as the development medium. When the host computer performs wireless transmission, the way of receiving data can be one or more of GSM, ZigBee, GPRS, and the design process can be seen from the figure below. The three wireless detection subsystems of ZigBee, GPRS, and GSM are the main components of the upper computer software (Pimentel D., et al., 2004)

\section{EXPERIMENTAL RESULTS AND ANALYSIS}

Under the conditions of $47 \%$ relative humidity and 20 degrees Celsius of the ambient temperature, the Chinese Academy of Metrology, when the zero point and full-scale correction are both zero, measure $\mathrm{AD}$ acquisition 1 channel and frequency count 1 channel, and the results are shown in Table 2. (AD in the table corresponds to $\mathrm{AD}$ acquisition, $\mathrm{Fl}$ corresponds to frequency counting:

\subsection{ZigBee Mode Subsystem}

The data transmission method is selected to be sent by frame. Each frame of data sent is composed of the length and type of the data, the channel to obtain the data, the frame header, and the frame end, etc., to ensure that the host computer can easily analyze the data or analyze the data. The byte format sent using ASCII code can effectively increase the data transmission rate (Zsoldos F., et al.. 1987). The size of the ZigBee memory buffer will affect the size of each frame of data. The larger

Table 2. Data collected by $10 \mathrm{~m}$ distance system for AD 1 and FI 1 channels

\begin{tabular}{|c|c|c|c|c|c|c|c|c|}
\hline \multirow{2}{*}{$\begin{array}{c}\text { Standard } \\
\text { value }\end{array}$} & AD-1 & 0.000 & 0.500 & 1.000 & 1.500 & 2.000 & 3.000 & 4.000 \\
\cline { 2 - 9 } & FI-1 & 5 & 10 & 100 & 200 & 500 & 1000 & 5000 \\
\hline $\begin{array}{c}\text { Measuring } \\
\text { and } \\
\text { controlling } \\
\text { instrument }\end{array}$ & FD-1 & 0000 & 0478 & 0967 & 1466 & 1964 & 3002 & 3978 \\
\cline { 2 - 9 } & FI-1 & 00005 & 00009 & 00099 & 00198 & 00499 & 00998 & 04999 \\
\hline $\begin{array}{c}\text { Standard } \\
\text { value }\end{array}$ & AD-1 & 5.000 & 6.000 & 7.000 & 8.000 & 9.000 & 9.500 & \\
\cline { 2 - 10 } & FI-1 & 8000 & 10000 & 20000 & 30000 & 35000 & & \\
\hline $\begin{array}{c}\text { Measuring } \\
\text { and } \\
\text { controlling } \\
\text { instrument }\end{array}$ & AD-1 & 5004 & 5972 & 6989 & 8015 & 9012 & 9481 & \\
\cline { 2 - 9 } & FI-1 & 07999 & 09999 & 19999 & 29999 & 34998 & & \\
\hline
\end{tabular}


Figure 2. Flow chart of software design for measuring and controlling instrument

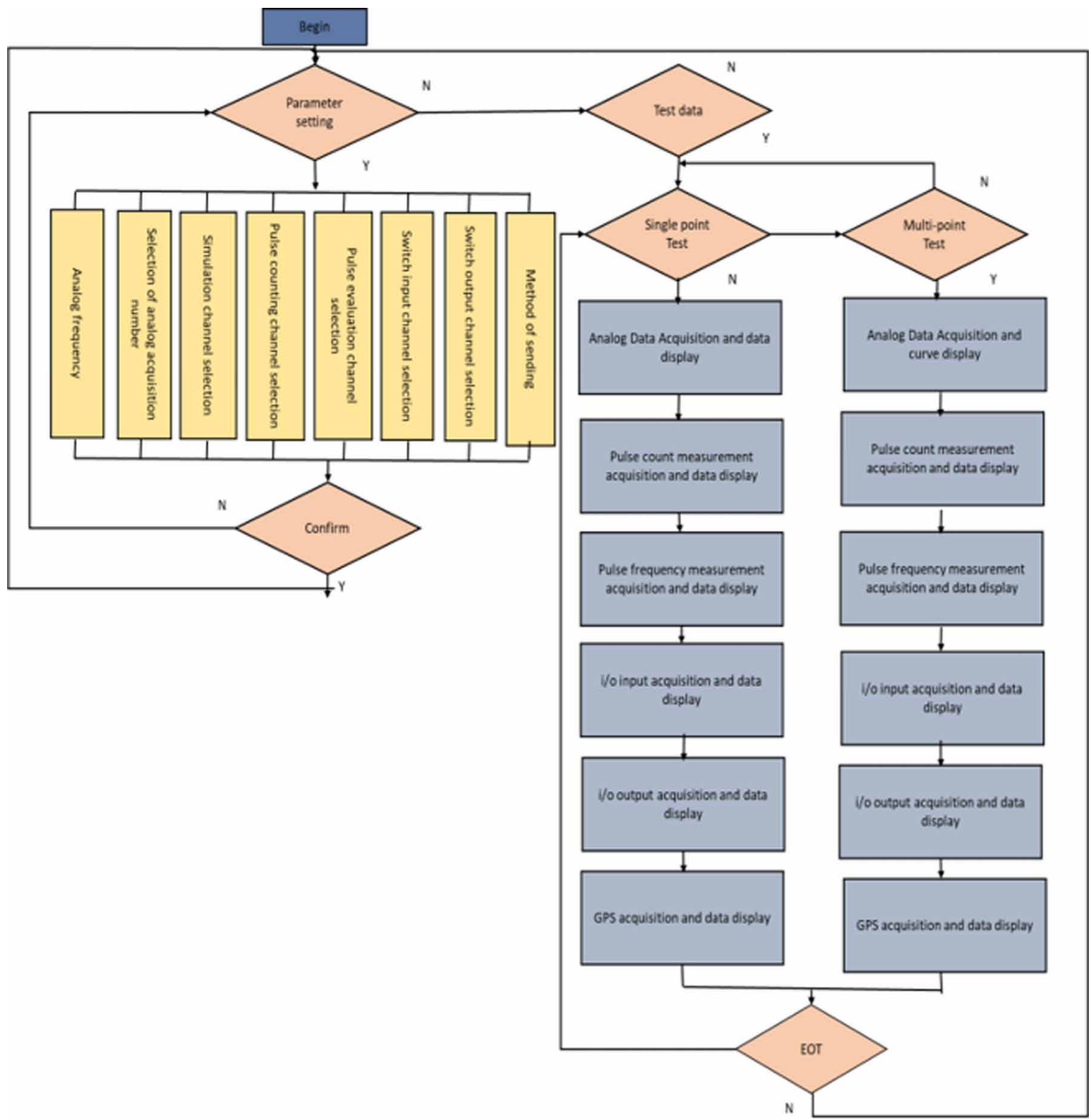

the memory buffer, the greater the upper limit of the data per frame, but it takes longer to accept. Figure 4 shows the plot of the 10m ZigBee mode subsystem for AD 1 and FI 1 channels. Shown in the table are the data collected by AD and Fl channels. Adding the flag bit data can make the lower computer filter the subroutine, thereby effectively separating the collected frame flag and data, reducing internal conflicts after data transmission

\subsection{GPRS Mode Subsystem}

The GPRS subsystem is similar to the above-mentioned subsystem software. The concept of the communication protocol is similar. The only and biggest difference is that the upper and lower computers in the GPRS subsystem communicate with the GSM network as the core, and there are more nodes in the network than ZigBee. So the communication speed is slower. To cope with the poor signal of the mobile phone, when the GPRS system uses network transmission, there is a module in the 
Table 3. Data collected by the $10 \mathrm{~m}$ ZigBee mode subsystem for AD 1 and FI 1 channels

\begin{tabular}{|c|c|c|c|c|c|c|c|c|}
\hline ZigBee & AD-1 & $\mathbf{0 . 0 0 0}$ & $\mathbf{0 . 4 7 0}$ & $\mathbf{0 . 9 7 0}$ & $\mathbf{1 . 4 6 9}$ & $\mathbf{1 . 9 6 9}$ & $\mathbf{3 . 0 0 7}$ & $\mathbf{3 . 9 7 6}$ \\
\hline \multirow{3}{*}{} & FI-1 & 00005 & 00009 & 00099 & 00198 & 00499 & 00998 & 04999 \\
\cline { 2 - 9 } & AD-1 & 5.005 & 5.984 & 6.993 & 8.021 & 9.030 & 9.500 & \\
\cline { 2 - 9 } & FI-1 & 07999 & 09999 & 19999 & 29999 & 34998 & & \\
\hline
\end{tabular}

Figure 3. Flow chart of upper computer software development

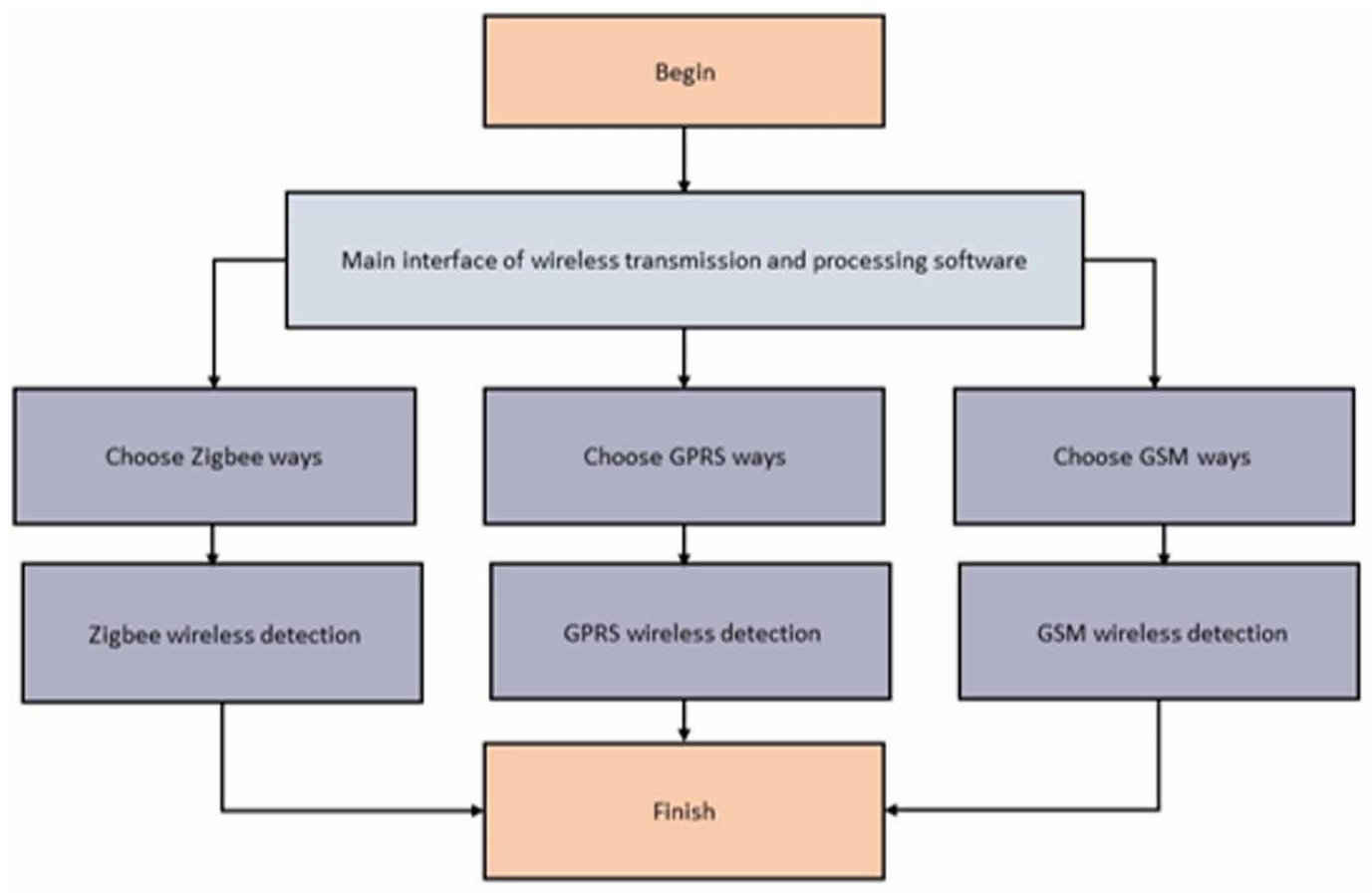

lower computer to enhance the signal interruption data buffer function; when the signal temporarily disappears or there is no signal, the GPRS subsystem will not stop working. It will continue to collect data and store it in the memory of the portable measurement and control instrument until the signal appears, and then return to the normal mode of wireless transmission. (Lakhiar, I. A. et al., 2018).

The lower computer can encode the transmitted data twice, mainly relying on the PDU transmission mode (Aqeel R. et al., 2009). This mode can select the transmission data according to its own needs, which enhances the directivity of the data and improves the efficiency of the data transmission (Werheit, P. et al.,2011). There are certain defects in the work of the GPRS subsystem. Figure 5 indicates the plot of the 10m GPRS mode subsystem for AD 1 and FI 1 channels. Errors and other situations require data decoding and secondary encoding, resulting in large communication delays. Therefore, to improve the communication efficiency of the system, the lower computer needs to filter some subroutines when collecting data. The collected data is shown in the table below.

\subsection{GSM Mode Subsystem}

The functions and communication protocols of the GSM subsystem are similar to those of the other two methods, but it cannot collect data continuously. The GSM subsystem uses two different modes 
Figure 4. Plot of $10 \mathrm{~m}$ ZigBee mode subsystem for $A D 1$ and FI 1 channels

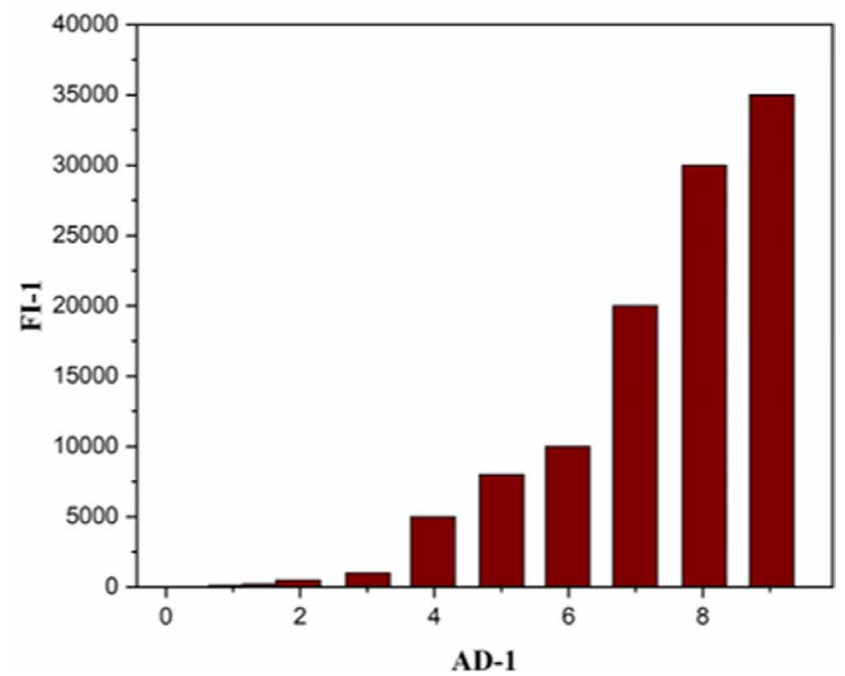

Table 4. Data collected by the $10 \mathrm{~m}$ GPRS mode subsystem for AD 1 and FI 1 channels

\begin{tabular}{|c|c|c|c|c|c|c|c|c|}
\hline \multirow{4}{*}{ GPRS } & AD-1 & 0.000 & 0.470 & 0.970 & 1.469 & 1.969 & 3.007 & 3.976 \\
\cline { 2 - 10 } & FI-1 & 00005 & 00009 & 00099 & 00198 & 00499 & 00998 & 04999 \\
\cline { 2 - 10 } & AD-1 & 5.005 & 5.984 & 6.993 & 8.021 & 9.030 & 9.500 & \\
\cline { 2 - 10 } & FI-1 & 07999 & 09999 & 19999 & 29999 & 34998 & & \\
\hline
\end{tabular}

Figure 5. Plot of the 10m GPRS mode subsystem for $A D 1$ and FI 1 channels

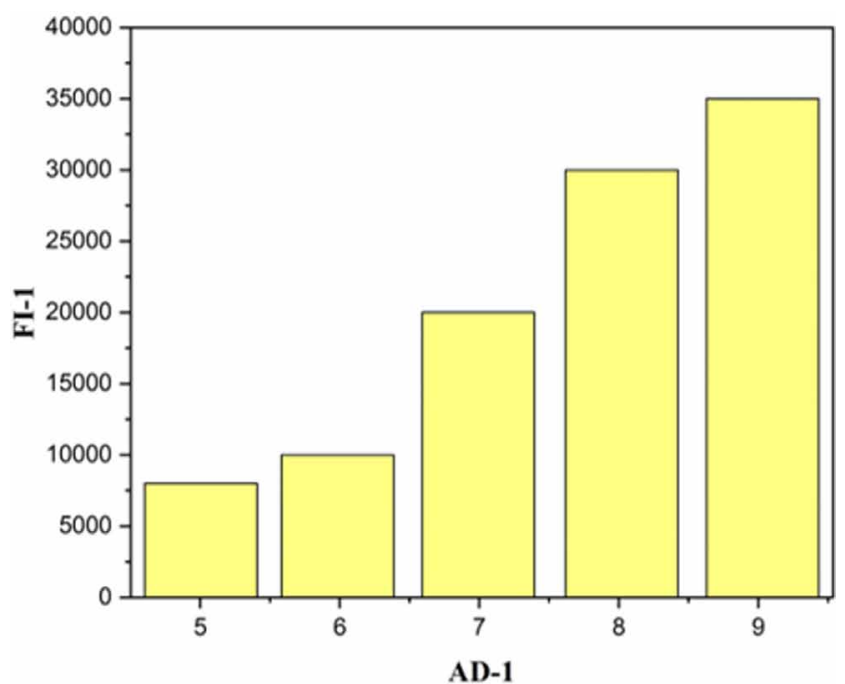


when sending and receiving data (Basnet B. et al.2018). It is worth noting that the lower computer is in the text mode when sending data. The upper computer needs to initialize all the receiving data modules before complete communication is established (Buer C. S., et al. 1996). Table 5 shows the data collected by the subsystem ten meters away (Kumar D., et al.2019). It can be concluded from the above five tables that the data collected by the three types of subsystems are similar. It can be said that the wireless transmission data is reliable. Figure 6 shows the plot of the 10m GPRS mode subsystem for AD1 and FI 1 channels (Shidujaman, M. et al. 2014).

All errors come from the calculation errors of the upper computer and the lower computer in the measurement and control instrument that can be ignored (Ruiz-Garcia L., et al 2009; Zhang W., et al., 2004). It can also be seen from Table 5 that the AD and Fl channels are measured accurately. Taking 1 channel as an example, the linear error is only $0.38 \%$ and $0.006 \%$, respectively, and the resolution is $0.01 \mathrm{~V}$ and $1 \mathrm{H}$.

The performance evaluation is fully achieved with a qualified level of equipment testing when used in agriculture. The following table shows the data collected by the AD1 channel in different distance ranges. To simulate the working environment of agricultural equipment at work and achieve as realistic results as possible. The three modes of subsystems must be arranged in different locations, so the ZigBee and GSM subsystem host computer tests are selected outdoors, and the GPRS subsystem is tested indoors (Zobel R. W. et al.,1999). For computer testing, the distance between the lower computer and the upper computer for several sets of data is different. The lower computer is mainly responsible for collecting and sending data (Sani M. I., et al. 2016).

Cross-province* means that the GPRS mode subsystem can be used for data reception at this time; cross-province** means that only the GSM mode subsystem can be used for data reception at

Table 5. Data collected by the $10 \mathrm{~m}$ GSM mode subsystem for AD 1 and FI 1 channels

\begin{tabular}{|c|c|c|c|c|c|c|c|c|}
\hline & $\mathrm{AD}-1$ & 0.000 & 0.470 & 0.970 & 1.469 & 1.969 & 3.007 & 3.976 \\
\cline { 2 - 10 } GPRS & $\mathrm{FI}-1$ & 00005 & 00009 & 00099 & 00198 & 00499 & 00998 & 04999 \\
\cline { 2 - 10 } & $\mathrm{AD}-1$ & 5.005 & 5.984 & 6.993 & 8.021 & 9.030 & 9.500 & \\
\cline { 2 - 10 } & $\mathrm{FI}-1$ & 07999 & 09999 & 19999 & 29999 & 34998 & & \\
\hline
\end{tabular}

Figure 6. Plot of the $10 \mathrm{~m}$ GPRS mode subsystem for AD 1 and FI 1 channels

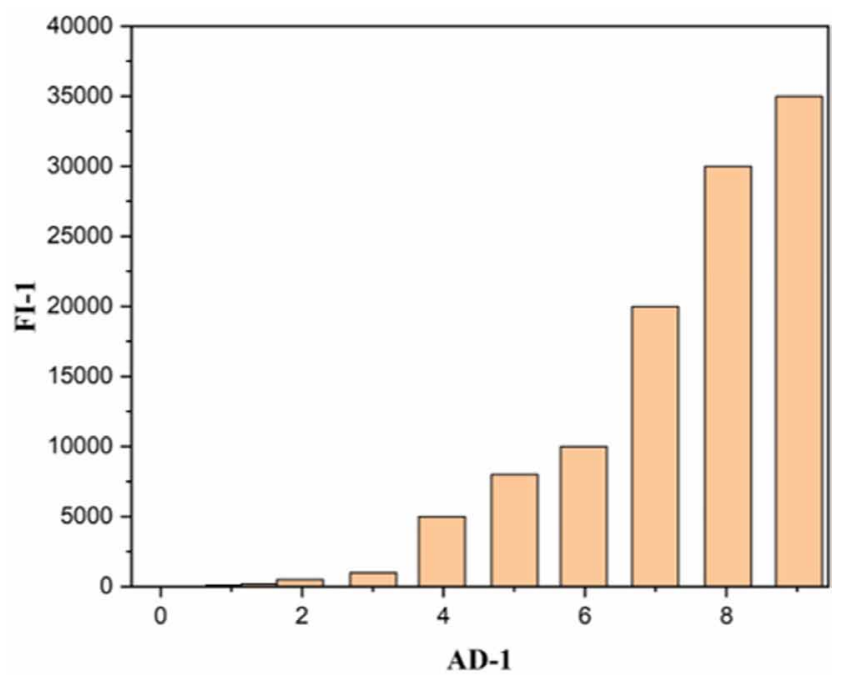


Table 6. Acquisition results of $A D 1$ Channel parameters at a different distance range

\begin{tabular}{|c|c|c|c|c|}
\hline $\begin{array}{c}\text { Transmission } \\
\text { distance }\end{array}$ & $\begin{array}{c}\text { Measurement and control } \\
\text { instrument AD11mV }\end{array}$ & $\begin{array}{c}\text { ZigBee } \\
\text { AD1/V }\end{array}$ & $\begin{array}{c}\text { GPRS } \\
\text { AD1/V }\end{array}$ & $\begin{array}{c}\text { GSM } \\
\text { AD1/V }\end{array}$ \\
\hline $\mathbf{5 0 m}$ & 5.004 & 5.005 & 5.005 & 5.005 \\
\hline $\mathbf{1 0 0 m}$ & 4.995 & 4.996 & 4.996 & 4.996 \\
\hline $\mathbf{5 k m}$ & 4.987 & & 4.988 & 4.988 \\
\hline Interprovincial* & 4.995 & & 4.996 & 4.996 \\
\hline Interprovincial** & 5.004 & & & 5.005 \\
\hline
\end{tabular}

Note: The standard voltage when testing data in the table is all five volts, and each data is collected ten times and the average value is taken to reduce the influence of errors and accidental data;

this time. The above methods cannot be used; the test delay is determined by a specific method (Yue, et al., 2012). Make the upper computer and the lower computer process the data in the same position, which is the delayed test (Zheng, X., et al., 2019).

From the analysis of the data results in the above five tables, we can get:

- Both GSM and GPRS subsystems can complete accurate data transmission within short and long distances. The GSM method will not be restricted by the local network conditions during the experiment. Unlike these two methods, the ZigBee subsystem can only be accurate data transmission within one hundred meters (Bhalaik S, et al. 2020).

- The measurement accuracy of this equipment is accurate. Whether indoors or outdoors, the average error of the measurement data is lower than the allowable error value of the laboratory. The measurement is accurate, so this equipment has a high degree of reliability and can be used for agricultural equipment promotion (Sharma A., et al., 2019).

\section{CONCLUSION}

This article aims to use wireless transmission methods to complete the measurement and evaluation of agricultural equipment. To reasonably use ZigBee, GPRS, and GSM three modes of subsystems for data transmission, accurately achieve the data collection and analysis of agricultural equipment, and improve the performance of agricultural equipment. Own quality and automation level.

This equipment can accurately retrieve equipment information status, measure equipment parameters, achieve wireless data transmission, and realize the perfect handover between equipment and data, which greatly improves the utilization rate of the detection device and reduces the number of inspection sites. The equipment is mainly used in a piece of farmland, so the probability of interference is minimal, and the transmission is transparent and efficient. This equipment not only solves the various difficulties encountered in the detection of agricultural equipment by traditional means but also strengthens the monitoring and management of agricultural equipment. It also makes agricultural equipment resistant to interference, easy wiring, convenient maintenance, unobstructed transmission, and diverse functions. Tracking the positioning coordinates and usage status of agricultural equipment at any time has significantly improved. Its level of intelligence rationally used contemporary hightech technologies and made a major contribution to the advancement of agricultural equipment. To welcome the arrival of the $5 \mathrm{G}$ era, realize the Internet of everything laying a good foundation is a big step for China to develop together with agriculture in the future and lead the world. 


\section{REFERENCES}

Adamchuk, V. I., Hummel, J. W., Morgan, M. T., \& Upadhyaya, S. K. (2004). On-the-go soil sensors for precision agriculture. Computers and Electronics in Agriculture, 44(1), 71-91. doi:10.1016/j.compag.2004.03.002

Aqeel, R. (2009). Smart agriculture. Application of Modern High-Performance Networks, 120-129.

Basnet, B., \& Bang, J. (2018). The state-of-the-art of knowledge intensive agriculture: A review on applied sensing systems and data analytics. Journal of Sensors, 1-13.

Bhalaik, S., Sharma, A., Kumar, R., \& Sharma, N. (2020). Performance modeling and Analysis of WDM Optical Networks under Wavelength Continuity Constraint using MILP. Recent Advances in Electrical \& Electronic Engineering, 13(2), 203-211. doi:10.2174/2352096512666190214105927

Brasse, T. (2006). Precision Agriculture (1st ed.). Thomson Delmar Learning.

Buer, C. S., Correll, M. J., Smith, T. C., Towler, M. J., Weathers, P. J., Nadler, M., Seaman, J., \& Walcerz, D. (1996). Development of a nontoxic acoustic window nutrient-mist bioreactor and relevant growth data. In Vitro Cellular \& Developmental Biology. Plant, 32(4), 299-304. doi:10.1007/BF02822703

Buttafuoco, G., \& Lucà, F. (2016). The Contribution of Geostatistics to Precision Agriculture. Ann. Agric. Crop Sci., 1, 1008-1009.

Cossell, S., Whitty, M., Liu, S., \& Tang, J. (2016). Spatial Map Generation from Low Cost Ground Vehicle Mounted Monocular Camera. IFAC-PapersOnLine, 49(16), 231-236. doi:10.1016/j.ifacol.2016.10.043

De Wagter, C., Ruijsink, R., Smeur, E. J. J., van Hecke, K. G., van Tienen, F., van der Horst, E., \& Remes, B. D. W. (2018). Design, control, and visual navigation of the DelftaCopter VTOL tail-sitter UAV. Journal of Field Robotics, 35(6), 937-960. doi:10.1002/rob.21789

Hessel, M. I., Richert, G. E., \& Nevill, J. G. E. (n.d.). Airflow-contained aeroponic nutrient delivery for a microgravity plant growth unit. Biotronics, 21, 33-38.

Jiang, Y., Liu, Z., Li, Y., Li, J., Lian, Y., Liao, N., Li, Z., \& Zhao, Z. (2020). A Digital Grayscale Generation Equipment for Image Display Standardization. Applied Sciences (Basel, Switzerland), 10(7), 2297. doi:10.3390/ app10072297

Kumar, D., Sharma, A., Kumar, R., \& Sharma, N. (2019). Restoration of the Network for Next Generation (5G) Optical Communication Network. 2019 International Conference on Signal Processing and Communication (ICSC), 64-68. doi:10.1109/ICSC45622.2019.8938337

Lakhiar, I. A. X. (2018). Experimental study of ultrasonic atomizer effects on values of EC and pH of nutrient solution. International Journal of Agricultural and Biological Engineering, 11(5), 59-64. doi:10.25165/j. ijabe.20181105.3790

Laksono, P., Idris, I. M., Sani, I., \& Putra, D. N. (2014). Lab prototype of wireless monitoring and control for seed potatoes growing chamber. Proceedings of the Asia-Pacific Advanced Network, 37(0), 20-29. doi:10.7125/ APAN.37.3

Mallampati, S. R., Lee, B. H., Mitoma, Y., \& Simion, C. (2018). Sustainable recovery of precious metals from end-of-life vehicles shredder residue by a novel hybrid ball-milling and nanoparticles enabled froth flotation process. Journal of Cleaner Production, 171, 66-75. doi:10.1016/j.jclepro.2017.09.279

Mbiyu, M. W., Muthoni, J., \& Kabira, J. (2012). Use of aeroponics technique for potato (Solanum tuberosum) minitubers production in Kenya. Journal of Horticulture and Forestry, 4, 172-177.

Merk, S., Scholz, C., Florek, S., \& Mory, D. (2015). Increased identification rate of scrap metal using Laser Induced Breakdown Spectroscopy Echelle spectra. Spectrochim. Acta - Part B At. Spectrosc, 112, 10-15. .sab.2015.07.00910.1016/j

Mesina, M. B., De Jong, T. P. R., \& Dalmijn, W. L. (2003). Improvements in separation of non-ferrous scrap metals using an electromagnetic sensor. Physical Separation in Science and Engineering, 12(2), 87-101. doi:10.1080/1478647031000139079 
Oliver, M., \& Webster, R. (2014). A tutorial guide to Geostatistics: Computing and modelling variograms and kriging. Catena, 113, 56-69. doi:10.1016/j.catena.2013.09.006

Pala, M., Mizenko, L., Mach, M., \& Reed, T. (2014). Aeroponic greenhouse as an autonomous system using intelligent space for agriculture robotics. In J. H. Kim, E. Matson, H. Myung, P. Xu, \& F. Karray (Eds.), Robot Intelligence Technology and Applications 2. Advances in Intelligent Systems and Computing, 274 (pp. 83-93). doi:10.1007/978-3-319-05582-4_7

Pimentel, D., Berger, B., Filiberto, D., Newton, M., Wolfe, B., Karabinakis, E., Clark, S., Poon, E., Abbett, E., \& Nandagopal, S. (2004). Water resources: Agricultural and environmental issues. Bioscience, 54(10), 909-918. doi:10.1641/0006-3568(2004)054[0909:WRAAEI]2.0.CO;2

Rao, Z., Zhang, Z., Huang, S., Long, Z., \& Wu, G. (2020). Characteristics and Current Harmonic Control of N* Three-Phase PMSG for HVDC Transmission Based on MMC. Energies, 13(1), 178. doi:10.3390/en13010178

Rathee, G., Sharma, A., Kumar, R., Ahmad, F., \& Iqbal, R. (2020). A trust management scheme to secure mobile information centric networks. Computer Communications, 151, 66-75. doi:10.1016/j.comcom.2019.12.024

Raviv, M., \& Lieth, L. (2007). Significance of soilless culture in agriculture. In M. Raviv \& J. H. Lieth (Eds.), Soilless Culture: Theory and Practice (pp. 117-156). Elsevier.

Ruiz-Garcia, L., Lunadei, L., Barreiro, P., \& Robla, I. (2009). A review of wireless sensor technologies and applications in agriculture and food industry: State of the art and current trends. Sensors (Basel), 9(6), 9472894750. doi:10.3390/s90604728 PMID:22408551

Saiz-Rubio, V., \& Rovira-Más, F. (2013). Proximal sensing mapping method to generate field maps in vineyards. Agricultural Engineering International: CIGR Journal, 15, 47-59.

Sani, M. I., Siregar, S., Kurniawan, A. P., Jauhari, R., \& Mandalahi, C. N. (2016). Web-based monitoring and control system for aeroponics growing chamber. 2016 International Conference on Control, Electronics, Renewable Energy and Communications (ICCEREC), 162-168.

Sharma, A., Kumar, R., \& Kaur, P. (2019). Study of Issues and Challenges of Different Routing Protocols in Wireless Sensor Network. Fifth International Conference on Image Information Processing (ICIIP), 85-590. doi:10.1109/ICIIP47207.2019.8985915

Shidujaman, M., Samani, H., \& Arif, M. (2014). Wireless power transmission trends. 2014 International Conference on Informatics, Electronics \& Vision (ICIEV), 1-6. doi:10.1109/ICIEV.2014.6850770

Smith, Y. R., Nagel, J. R., \& Rajamani, R. K. (2019). Eddy current separation for recovery of non-ferrous metallic particles: A comprehensive review. Minerals Engineering, 133, 149-159. doi:10.1016/j.mineng.2018.12.025

Spencer, D. B. (2005). The high-speed identification and sorting of nonferrous scrap. JOM, 57(4), 46-51. doi:10.1007/s11837-005-0081-6

Teimouri, N., Omid, M., Mollazade, K., Mousazadeh, H., Alimardani, R., \& Karstoft, H. (2018). On-line separation and sorting of chicken portions using a robust visionbased intelligent modelling approach. Biosystems Engineering, 167, 8-20. doi:10.1016/j.biosystemseng.2017.12.009

Tik, L. B., Khuan, C. T., \& Palaniappan, S. (2009). Monitoring of an aeroponic greenhouse with a sensor network. IJCSNS International Journal of Computer Science and Network Security, 9, 240-246.

Tripathi, S., \& De, S. (2018). Dynamic Prediction of Powerline Frequency for Wide Area Monitoring and Control. IEEE Transactions on Industrial Informatics, 14(7), 2837-2846. doi:10.1109/TII.2017.2777148

Wan, G., Li, F., Zhu, W., \& Wang, G. (2020). High-precision six-degree-of-freedom pose measurement and grasping system for large-size object based on binocular vision. SR 40, 71-80. 10.1108/SR-05-2019-0123

Wang, C., Hu, Z., Pang, Q., \& Hua, L. (2019). Research on the classification algorithm and operation parameters optimization of the system for separating non-ferrous metals from end-of-life vehicles based on machine vision. Waste Management (New York, N.Y.), 100, 10-17. doi:10.1016/j.wasman.2019.08.043 PMID:31493684

Werheit, P., Fricke-Begemann, C., Gesing, M., \& Noll, R. (2011). Fast single piece identification with a 3D scanning LIBS for aluminium cast and wrought alloys recycling. Journal of Analytical Atomic Spectrometry, 26(11), 2166-2174. doi:10.1039/c1ja10096c 
Yue, Q., Wang, H.M., \& Lu, Z.W. (2012). Quantitative estimation of social stock for metals Al and Cu in China. Trans. Nonferrous Met. Soc. China, 22(7), 1744-1752. (11)61382-410.1016/S1003-6326

Zhang, C., \& Chen, M. (2018a). Designing and verifying a disassembly line approach to cope with the upsurge of end-of-life vehicles in China. Waste Management (New York, N.Y.), 76, 697-707. doi:10.1016/j. wasman.2018.02.031 PMID:29472152

Zhang, C., \& Chen, M. (2018b). Prioritising alternatives for sustainable end-of-life vehicle disassembly in China using AHP methodology. Technology Analysis and Strategic Management, 30(5), 556-568. doi:10.1080/0953 7325.2017.1340640

Zhang, J., Song, W., Jiang, B., \& Li, M. (2018). Measurement of lumber moisture content based on PCA and GS-SVM. J. For. Res., 29(2), 557-564. doi:10.1007/s11676-017-0448-x

Zhang, W., Kantor, G., \& Singh, S. (2004). Integrated wireless sensor/actuator networks in an agricultural application. Proceedings of the 2nd international conference on Embedded networked sensor systems - SenSys '04.

Zheng, X., Li, Y., Liu, Z., \& Wang, C. (2019). Steady-state control strategy of VSC-HVDC transmission system based on full-order terminal sliding mode control method. Journal of Engineering (Stevenage, England), 987-990(16), 987-990. Advance online publication. doi:10.1049/joe.2018.8463

Zobel, R. W., \& Lychalk, R. F. (1999). Aeroponic growth system with nutrient fog stabilization. US Patent US5937575A.

Zsoldos, F., Vashegyi, A., \& Erdei, L. (1987). Lack of active K+ uptake in aeroponically grown wheat seedlings. Physiologia Plantarum, 71(3), 359-364. doi:10.1111/j.1399-3054.1987.tb04356.x

Fan Wu is currently pursuing his degree from School of Electrical Engineering, Yancheng Institute of Technology. his research area lies in wireless communication.

Aiqin $\mathrm{Li}$ is pursuing his degree from School of Electrical Engineering, Yancheng Institute of Technology and his research area lies in wireless communication.

Saihua $\mathrm{He}$ is associated with Jiangsu Linyang Energy Co., Ltd and his research rea lies in wireless communication.

Mohamed Sharaf is a specialist in modeling, design and simulation of renewable desalination systems. He is awarded the $\mathrm{PhD}$ in design and simulation of solar desalination systems. His master degree was in the field of manufacturing a small solar desalination unit (solar-MSF type). He awarded his B.Sc degree in mechanical engineering. Currently, he is a full time teacher at the University of Suez-the College of Petroleum and Mining Energy Engineering Department. He is also a member of the Board of Suez and Engineers Association official of the Cultural Committee. He is a permanent reviewer (Editorial Board Member) of Modern Applied Science JournalCanadian Center of Science and Education. He also participated in several international projects with the European Union in the field of solar energy and water desalination. Moreover; he has many of the research papers in the field of solar desalination. He has awarded a top reviewer certificate in 2011 and 2012 from Desalination Journal. 